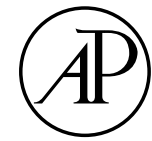

\title{
A matter of time: evaluating the storage of fecal samples for steroid analysis
}

\author{
M.Z. Khan, ${ }^{\mathrm{a}, *}$ J. Altmann, ${ }^{\mathrm{a}, \mathrm{b}, \mathrm{c}}$ S.S. Isani, ${ }^{\mathrm{a}}$ and J. $\mathrm{Yu}^{\mathrm{a}}$ \\ ${ }^{a}$ Department of Ecology and Evolutionary Biology, Princeton University, Princeton, NJ 08544, USA \\ ${ }^{\mathrm{b}}$ Chicago Zoological Society, USA \\ ${ }^{\mathrm{c}}$ Institute of Primate Research, National Museums of Kenya, Kenya
}

Accepted 6 June 2002

\section{Abstract}

The extraction and immunoassay of fecal steroids is an increasingly common technique, used in both captive and field studies to provide an approximation of an animal's circulating concentration of hormones through non-invasive methods. Storage of fecal samples is of critical concern because fecal bacteria metabolize fecal steroids within hours after deposit. Ethanol is often used as a preservative for fecal samples stored for several hours at room temperature. We examined the stability of fecal estrogen (fE) and glucocorticoid (fGC) metabolites from baboon (Papio cynocephalus) samples in a 95\% ethanol solution at ambient temperature and at $-20^{\circ} \mathrm{C}$ over the course of six months, to determine the effect of storage on steroid concentrations. As measured by radioimmunoassay, fE metabolite concentrations increased by $122 \%$ at 90 days and fGC metabolite concentrations increased by $92 \%$ at 120 days. After peaking, both hormones declined to near initial concentrations by 180 days in ambient temperature samples. In samples stored at sub-zero temperatures, fGC metabolite concentrations showed a similar but dampened pattern, while fE metabolite concentrations exhibited small and variable changes with no consistent trend. We discuss explanations for the dynamic pattern of changing fecal metabolite concentrations and offer practical and analytical guidance to field workers for situations in which ideal conditions for stabilizing hormones are not available. (c) 2002 Elsevier Science (USA). All rights reserved.

\section{Keywords: Fecal steroids; Estrogens; Glucocorticoids; Storage; Ethanol; Baboon}

\section{Introduction}

Fecal steroid measurement is a valuable non-invasive tool for assessing reproduction, environmental stress, and aggression in populations of captive and free-living animals (reviewed in Whitten et al., 1998). In captive settings, fecal samples are collected and frozen immediately (Graham and Brown, 1996; Hamilton et al., 2000; Sousa and Ziegler, 1998; Wallner et al., 1999). Fecal samples, as with most biological samples, are most stable over time when stored at sub-zero temperatures (Whitten et al., 1998). When a cooling mechanism is available, cold storage is the preferred method for fecal sample preservation in the field. Some methods for preserving feces in field conditions include immediate

\footnotetext{
${ }^{*}$ Corresponding author. Present address: 2640 Dunham Road, Utica, NY 13501, USA.

E-mail address: mkhan@princeton.edu (M.Z. Khan).
}

freezing in liquid nitrogen (Creel et al., 1997; Wasser et al., 1988), storage in ethanol in a $-20^{\circ} \mathrm{C}$ freezer (Strier and Ziegler, 1997; Wasser, 1996; Wasser et al., 1997), and field extraction, followed by storage of the extract at sub-zero temperatures (Lynch et al., 2002; Stavisky et al., 1995; Strier et al., 1999). However, liquid nitrogen, dry ice, or freezers are not always available in the field.

If the feces are not treated with preservatives or kept in cold storage, naturally occurring bacteria and bacterial enzymes in feces decompose steroid metabolites within hours after defecation (Moestl et al., 1999; Wasser et al., 1988). Wasser et al. (1988) demonstrated that ethanol stabilizes fecal estrogens and progestins over a period of $21 \mathrm{~h}$ at ambient temperatures, presumably by killing bacteria and inactivating their associated enzymes. Subsequently, ethanol either alone or with sodium azide has been used as a preservative for short-term ambient temperature storage of fecal samples (Strier and Ziegler, 1997; Wasser, 1996; Wasser et al., 
56 1997; Ziegler et al., 2000) or long-term storage for 5 57 months (Cavigelli, 1999) to 3.5 years (Curtis et al., 58 2000). Other ambient temperature field storage tech59 niques include oven-drying samples (Brockman and 60 Whitten, 1996; Brockman et al., 1998). After oven-dry61 ing, estradiol and testosterone showed complete stability 62 after 3 weeks, while progesterone showed less stability 63 (Brockman and Whitten, 1996). Comprehensive tests of 64 the efficacy of these storage methods have not been 65 conducted (Whitten et al., 1998), resulting in a scarcity 66 of practical information about viable storage techniques 67 under field conditions (Table 1).

68 Our goal in this study was to determine the effects of 69 storage over the course of 180 days, on a well-mixed 70 pool of feces collected from a captive group of baboons. 71 Here, we present results from a study that examines the 72 long-term stability of fecal estrogen and glucocorticoid 73 metabolites from baboon samples in an ethanol solution 74 at ambient temperature $\left(25^{\circ} \mathrm{C}\right)$ and at sub-zero tem75 peratures $\left(-20^{\circ} \mathrm{C}\right)$.

\section{2. Materials and methods}

For validation of assays, we used freshly collected feces from wild- and captive-living baboons (Papio $c y$ nocephalus). For the storage experiment, to use a large quantity of feces from which many replicates could be analyzed across 180 days, we used approximately $1 \mathrm{~kg}$ of feces, which was collected from 5 to 7 captive adult male and female baboons. These individuals were members of a group of approximately 60 individuals that live in a large, semi-natural enclosure at Brookfield Zoo (Chicago Zoological Society). As a result of tubal ligation of females and vasectomies of males, no females in the colony were pregnant or lactating at time. Fresh samples were mixed thoroughly, frozen immediately, and sent on dry ice to Princeton University. The feces were thawed, mixed again and divided among 130 polypropylene vials in $4-\mathrm{g}$ aliquots. Ten replicates were freeze-dried immediately and analyzed to provide baseline measurements for estrogen and cortisol metabolites. The remaining 120 samples were placed in 95\% ethanol $(2.5 \mathrm{ml}$ ethanol:1 $\mathrm{g}$ feces $)$. These samples were divided into two treatment groups: (1) storage at ambient temperature (on average $25^{\circ} \mathrm{C}$ ) or (2) storage at sub-zero temperatures (on average $-20^{\circ} \mathrm{C}$ ). For the glucocorticoid and estrogen study, 10 replicates were freeze-dried and assayed at 30-day intervals for the first 120 days. For the glucocorticoid study, five replicates were freeze-dried and assayed at 15-day intervals between 120 and 165 days, while the number of replicates remained 10 and the interval remained at 30-days for the estrogen experiment. The greater frequency of assaying for glucocorticoids than estrogens resulted in smaller samples sizes per assay for the glucocorticoid study. We shortened the storage intervals to ensure that we observed the peak and decline in fecal steroid concentrations for the glucocorticoid study. Both experiments concluded at 180 days when the remaining 10 replicates were freeze-dried and assayed.

Processing of fecal samples. At Princeton University, ethanol was evaporated by placing each sample under a hood, at ambient temperature, overnight. Then the samples were freeze-dried, to ensure complete dryness, and sifted through fine mesh (40 mesh). About $0.2 \mathrm{~g}$ of each sample was extracted into $2 \mathrm{ml}$ of $90 \%$ methanol by vortexing on a multi-pulse vortexer (Glas-Col, Terre Haute, IN; pulse rate $1 / \mathrm{s}$, speed 70 ) for $30 \mathrm{~min}$. The mixture was centrifuged for $20 \mathrm{~min}$ at a force of $1 \mathrm{~g}$ and

Table 1

Reported length of time fecal samples that have been stored at ambient temperature and the preservatives used

\begin{tabular}{|c|c|c|c|c|}
\hline Species & & Maximum time ambient & Preservative & Reference \\
\hline African wild dog & Lycaon pictus & None & Liquid nitrogen & Creel et al. (1997) \\
\hline Baboon & Papio cynocephalus & None, stored on ice & Liquid nitrogen & Wasser et al. (1988) \\
\hline Baboon & Papio cynocephalus & $2 \mathrm{~h}$ & $-20^{\circ} \mathrm{C}$ & Stavisky et al. (1995) \\
\hline Spotted owl & Strix occidentalis & $2-5 \mathrm{~h}$ & $90 \% \mathrm{EtOH}$ & Wasser et al. (1997) \\
\hline Ring-tailed lemur & Lemur catta & $3 \mathrm{~h}$ & None & Cavigelli and Pereira (2000) \\
\hline Hanuman langur & Presbytis entellus & $5 \mathrm{~h}$ & $90 \% \mathrm{EtOH}$ & Ziegler et al. (2000) \\
\hline Baboon & Papio cynocephalus & $8 \mathrm{~h}$ & $95 \% \mathrm{EtOH}$ & Wasser (1996) \\
\hline Muriqui & Brachyteles arachnoides & $10 \mathrm{~h}^{\mathrm{a}}$ & $\begin{array}{l}0.2 \% \mathrm{NaN}_{3} \\
95 \% \mathrm{EtOH}\end{array}$ & $\begin{array}{l}\text { Strier and Ziegler (1997) (see } \\
\text { newer technique, Strier et al., } \\
\text { 1999) }\end{array}$ \\
\hline Tule elk & Cervus elaphus nanodes & $12-14 \mathrm{~h}$ & $-20^{\circ} \mathrm{C}$ & Stoops et al. (1999) \\
\hline Baboon & Papio cynocephalus & $21 \mathrm{~h}^{\mathrm{b}}$ & $100 \% \mathrm{EtOH}$ & Wasser et al. (1988) \\
\hline Verraux's sifaka & Propithecus verreauxi & 3 weeks $^{\text {b }}$ & Silica dried & Brockman et al. (1998) \\
\hline Ring-tailed lemur & Lemur catta & 5 months $^{\mathrm{a}}$ & $\begin{array}{l}100 \% \mathrm{EtOH} \\
3 \% \mathrm{NaN}_{3}\end{array}$ & Cavigelli (1999) \\
\hline Mongoose lemur & Eulemur mongoz & 3.5 years & $96 \% \mathrm{EtOH}$ & Curtis et al. (2000) \\
\hline
\end{tabular}

\footnotetext{
${ }^{a}$ Results from validation experiment unpublished (verified by personal communication).
}

${ }^{\mathrm{b}}$ Validation experiment published in paper cited. 
123 the supernatant was transferred to a $2 \mathrm{ml}$ polypropyl124 ene storage tube with O-ring caps to prevent evapo125 ration. We assessed our extraction recovery of 126 corticosterone, and estradiol by adding $10,000 \mathrm{cpm}$ $127{ }^{125}$ I-labeled hormone to dry feces and incubating the 128 mixture at ambient temperature for, $1 \mathrm{~h}$ prior to 129 methanol extraction.

130 The methanol fecal extracts were stored at $-20^{\circ} \mathrm{C}$ 131 until they were assayed. Fecal samples were assayed in 132 duplicate, the results were averaged across duplicates, 133 and hormone concentrations were expressed as nanograms of hormone per gram of dry fecal matter.

Fecal glucocorticoid radioimmunoassay (RIA). We used a modified Corticosterone Kit for Rats and Mice (ICN Diagnostics, Cat No. 07-120-102, Costa Mesa, CA). The primary antibody has high cross-reactivities with the major cortisol metabolites present in baboon feces (Goymann et al., 1999; Wasser et al., 2000). This antibody has been validated for use with the baboon; it detects a rise in cortisol metabolites after a baboon is presented with an ACTH challenge (Wasser et al., 2000).

We validated the radioimmunoassay by running dilutions of a fecal extract pool $(1: 2,1: 4,1: 8,1: 10$, and 1:16) and comparing its slope to that of the standard curve. Samples were diluted 1:10 in assay buffer, prior to radioimmunoassay. Standards ranged from 0.125 to $5 \mathrm{ng} / \mathrm{ml}$. Internal controls consisted of a pooled fecal sample diluted 1:10 in assay buffer, frozen in small aliquots, stored at $-80^{\circ} \mathrm{C}$, and two controls provided with each kit, all of which were run in every assay. Intra- and inter-assay coefficients of variation $(\% \mathrm{CV}=[\mathrm{mean} /$ $\mathrm{SD}] * 100)$ were $4.4 \pm 1.0 \%$ (mean $\pm \mathrm{SE}$ ) and $10.8 \%$ for the fecal extract pool $(\sim 0.8 \mathrm{ng} / \mathrm{ml}), 2.5 \pm 0.5 \%$ and $8.7 \%$ for a low concentration control, and $2.5 \pm 0.5 \%$ and $9.8 \%$ for a high concentration control $(n=7$ for all controls). Mean assay accuracy (observed/expected*100) was $103.2 \pm S E 5.1 \%(n=4)$ and was assessed by running the $1.25 \mathrm{ng}$ standard as a sample.

Fecal estrogens RIA. We used a modified Total Estrogen Kit (ICN Diagnostics, Cat. No. 07-140-202, Costa Mesa, CA). Wasser et al. (1994) found that in the female baboon, $10 \%$ of radio-labeled estradiol injected into an individual was excreted in the feces with the remainder excreted in urine. The original radio-labeled estradiol was excreted in the feces as estradiol $(36 \%)$, estrone (44\%), and estrone sulfate $(20 \%$; Wasser et al., 1994). The primary antibody in this kit cross-reacts $100 \%$ with estradiol- $17 \beta$ and estrone, $9.0 \%$ with estriol, $7.0 \%$ with estradiol- $17 \alpha$, and $2.5 \%$ with equilin (ICN Diagnostics).

Prior to analysis, fecal extracts were extracted using solid-phase Oasis cartridges (Waters, Milford MA, WAT094226; techniques modified by T. E. Ziegler, University of Wisconsin). Fecal extract $(300 \mu \mathrm{l})$ was dried under nitrogen and reconstituted in $1 \mathrm{ml}$ of $30 \%$ methanol. Cartridges were conditioned with $1 \mathrm{ml}$ of $100 \%$ methanol, followed by $1 \mathrm{ml}$ distilled water. The $30 \%$ sample was loaded onto the cartridge, followed by $1 \mathrm{ml}$ of a $20 \%$ methanol rinse. The steroids were eluted off the column with $2 \mathrm{ml}$ of $100 \%$ methanol, which was collected, dried under nitrogen, and reconstituted in $300 \mu 1$ of $90 \%$ methanol to return the sample to its original volume in its original solute.

We validated the estrogen radioimmunoassay by running a serial dilution (1:20-1:1280) of baboon fecal extract pools and comparing the slope of the serial dilution to that of the standard curve. Samples were diluted 1:200 in assay buffer, prior to radioimmunoassay. Standards ranged from 5 to $200 \mathrm{pg} / \mathrm{ml}$. Intra- and interassay coefficients of variation were $4.5 \pm 1.4 \%$ and $9.0 \%$ for a fecal extract pool $(\sim 60 \mathrm{pg} / \mathrm{ml} ; n=7)$. Assay accuracy was $89.5 \pm$ SE $3.9 \%(n=4)$ and was assessed by running the $50 \mathrm{pg}$ standard as a sample.

\subsection{Statistical analysis}

All data were log transformed to meet assumptions of normality. Parallelism between standard curves and serial dilutions of fecal extracts was determined by a test of the equality of two slopes (Neter et al., 1990). Variation of fecal glucocorticoid and estrogen concentrations across time was analyzed with analysis of variance (ANOVA), followed by Tukey pairwise comparisons. Significance levels for all tests were set at $P \leqslant 0.05$. Means are given with standard errors unless otherwise noted.

\section{Results}

\subsection{Method validation}

Methanol extraction recoveries were $85.0 \pm 0.5 \%$ ( $n=10)$ for corticosterone and $92.3 \pm 0.5 \%(n=10)$ for estradiol. Solid phase extraction recovery of estradiol was assessed by assaying 10 replicate samples before and after solid phase extraction, yielding a recovery of $89.1 \pm 1.32 \%$.

The corticosterone standard curve was parallel to the displacement curve from the fecal extract serial dilution (Fig. 1A: Student's $t=0.16, p=0.87$ ). The total estrogens standard curve was parallel to the displacement curve from the fecal extract serial dilutions (Fig. 1B: Student's $t=0.35, p=0.73$ ).

Glucocorticoids. Fecal glucocorticoid concentrations varied with the number of days in storage for both the ambient temperature samples (Fig. 2A: $F=27.75$, $p<0.0001)$ and $-20^{\circ} \mathrm{C}$ samples $(F=20.82, p<0.0001)$.

Total estrogens. Fecal estrogen concentrations varied with the number of days in storage for both the ambient temperature samples (Fig. 2B: $F=54.14, p<0.0001$ ) and $-20^{\circ} \mathrm{C}$ samples $(F=9.68, p<0.0001)$.
197

208 

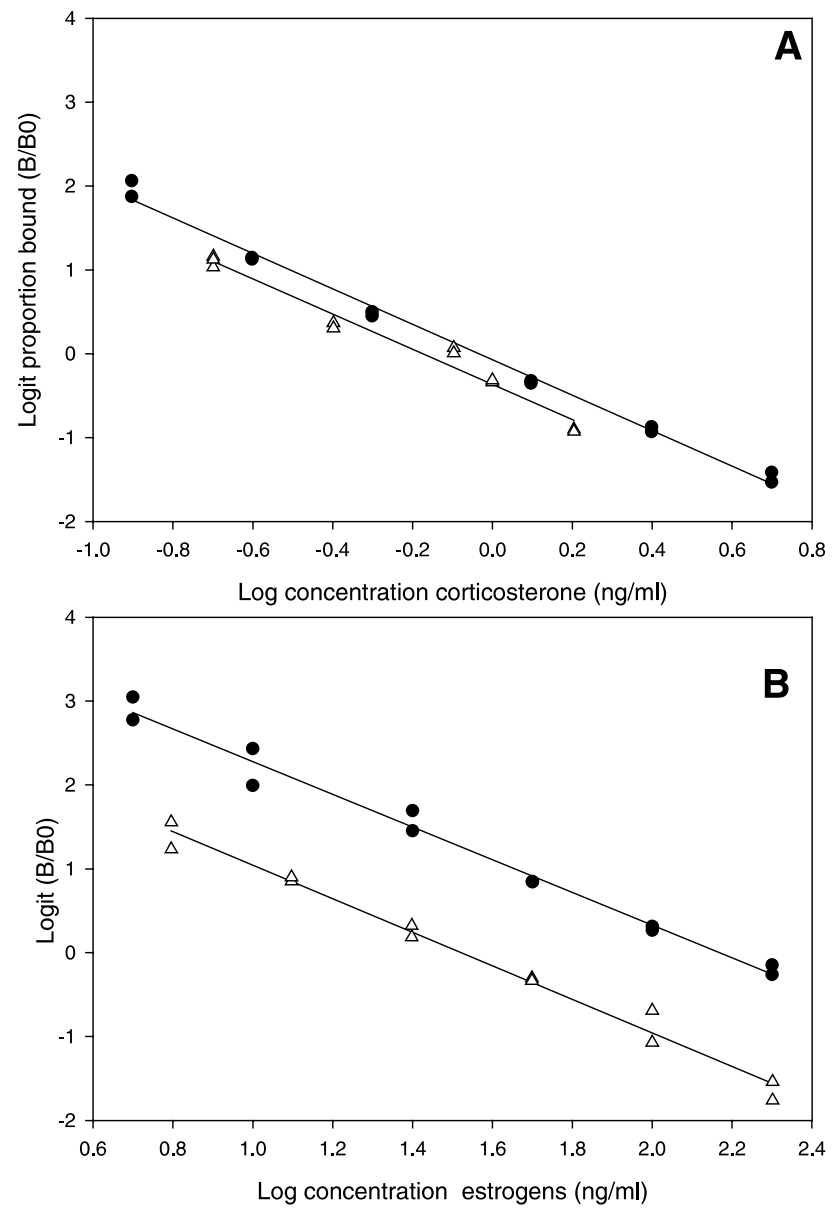

Fig. 1. (A) Log-logit transformed curves showing displacement of the binding of ${ }^{125}$ I-labeled corticosterone to ICN corticosterone antibody by corticosterone standard $(\bullet), y=-2.11 x-0.07, r^{2}=0.99$ and serial dilution of pooled fecal extract $(\triangle) y=-2.09-0.36, r^{2}=0.99$. (B) Log-logit transformed curves showing displacement of the binding of ${ }^{125}$ I-labeled estradiol to ICN total estrogen antibody by estradiol standard (@) $y=-1.95 x+4.80, r^{2}=0.99$, serial dilution of fecal extract pool $(\triangle) y=-1.99 x+3.04, r=0.98$.

\subsection{Magnitude of variability over time vs assay variability}

Inter-assay and intra-replicate variabilities are un-

231 likely explanations for the patterns of dynamic change 232 in either the fGC or fE studies. First, the maximum 233 percent change among quality control samples was 234 lower than the percent change observed among un235 known samples stored at ambient and sub-zero tem236 peratures (Table 2). Second, while inter-replicate 237 variability was low at most time periods for both stud238 ies, inter-replicate variability at peak fGC concentra239 tions was 5-9 times higher than the variability observed 240 at other points in time. The increased variation at these 241 time points is probably caused by subtle differences be242 tween the replicates, so that some were rising and others 243 were falling at these points in time. The increased vari244 ation during peak concentrations cannot be attributed
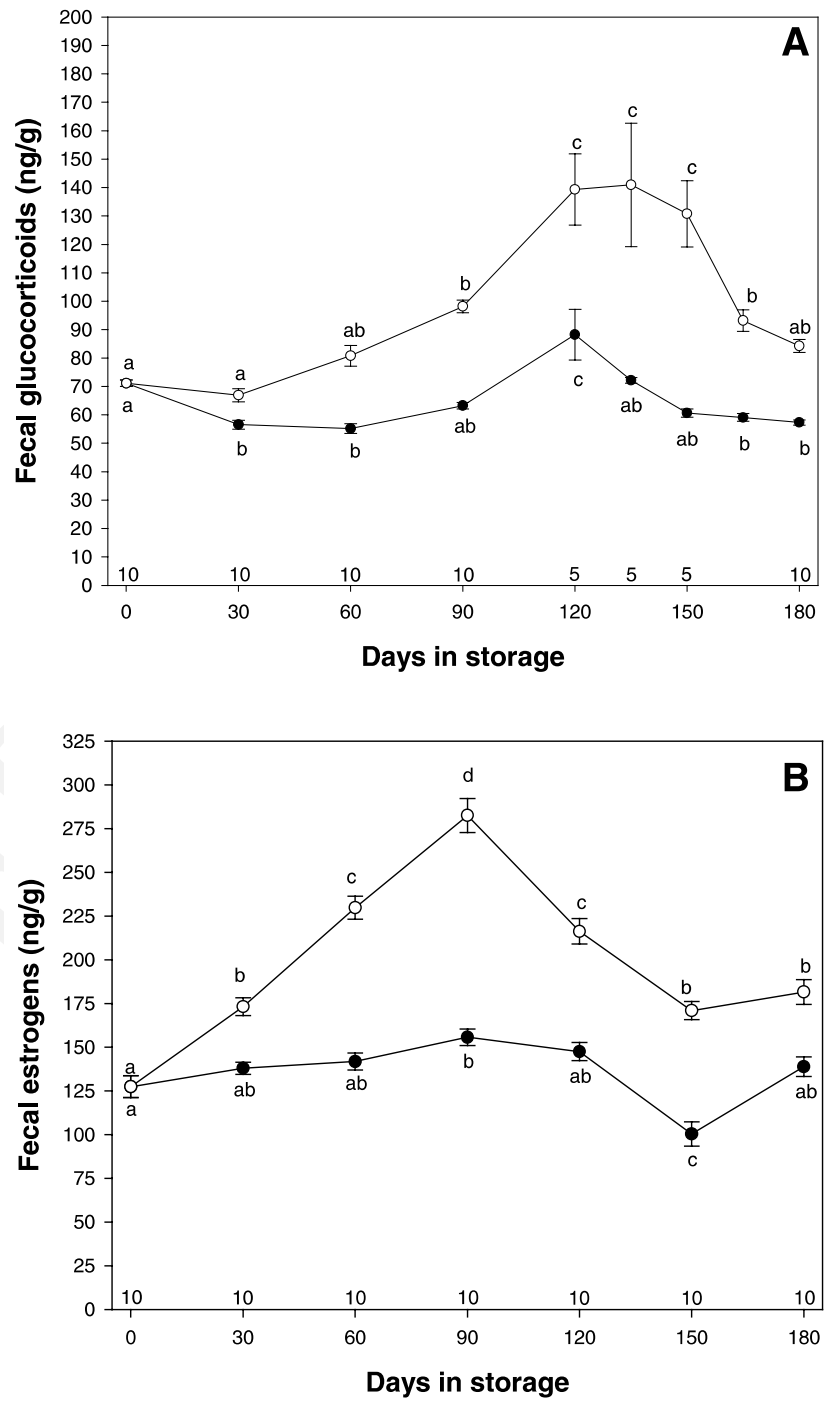

Fig. 2. (A) Change in fecal glucocorticoid metabolite concentration over time in captive baboon feces stored in ethanol at $-20^{\circ} \mathrm{C}$ (closed circles) and $25^{\circ} \mathrm{C}$ (open circles). (B) Change in fecal estrogens as a function of storage time in ethanol at $-20^{\circ} \mathrm{C}$ (closed circles) and $25^{\circ} \mathrm{C}$ (open circles). Statistical differences and similarities between groups are indicated with letters (Tukey's studentized range test, $p<0.05$ ). For example, initial concentrations of fGCs are not significantly different from concentrations measured after 30, 60, and 180 days of storage at ambient temperature. The number of replicates at each time point is indicated above the $x$-axis.

to methodological vagaries because the quality controls in these assays indicated high precision. Intra-assay variation during peak concentrations, days 120, 135, and 150 , was $4.2 \pm 1.2 \%$.

\section{Discussion}

Both the fGC and fE results showed marked changes over time in fecal samples stored at both ambient and sub-zero temperatures. This previously unappreciated variability has important implications for field storage 
Table 2

Percent variation in fGC and fE concentrations observed among quality control samples and storage experiment samples

\begin{tabular}{llllll}
\hline Maximum percent change & fGC & & & $\mathrm{fE}$ \\
\cline { 2 - 3 } \cline { 5 - 6 } \cline { 5 - 6 } & Ambient & Subzero & & Ambient & Subzero \\
\hline $\begin{array}{lllll}\text { Quality control pools } \\
\text { Storage samples }\end{array}$ & $12 \%$ & $12 \%$ & & $13 \%$ & $13 \%$ \\
Initial vs Peak & $92 \%$ & $17 \%$ & & $122 \%$ & $22 \%$ \\
Initial vs Nadir & $6 \% \%^{\mathrm{a}}$ & $29 \%$ & & $\mathrm{~N} / \mathrm{A}^{\mathrm{b}}$ & $21 \%$ \\
\hline
\end{tabular}

${ }^{\mathrm{a}}$ Nadir glucocorticoid concentrations among ambient temperature samples were not significantly different from initial concentrations.

${ }^{\mathrm{b}}$ Fecal estrogen concentrations never fell below initial concentrations among ambient temperature samples.

of samples for hormone analysis. Below, we discuss four options for researchers who wish to work with fecal steroids that were collected in difficult field situations.

First, these findings suggest rapid freezing of samples when possible, and if freezing is not possible, keeping samples at room temperature for no longer than 30 days if the hormones of interest are glucocorticoids, and for a shorter period if estrogens are the focus. If freezers are available, long-term storage of fecal samples in ethanol at $-20^{\circ} \mathrm{C}$ is more preferable than storage at room temperature; however, ideally it should not exceed 90-120 days.

Both the glucocorticoid and estrogen experiments might be interpreted as suggesting that ambient temperature storage for six months or longer may be advisable because the final concentrations of fGCs and fEs were approaching those of initial concentrations. However, before this strategy is employed one would need to validate, for the species and hormones of interest, whether steroid metabolites measured after six months at ambient temperature storage are an accurate reflection of plasma steroid levels at initial sampling time. Validation is necessary because molecules crossreacting with the antibody after six months may not be indicative of the physiological state of the animal at the time of sampling if chemical changes occurred within the sample.

The findings of the present study strongly point to the value of future studies of storage during the first month. These experiments would be conducted under actual field conditions, for each hormone of interest, and for samples that vary in initial hormone concentration. Such an experiment would validate the maximum storage duration and temperature regime that naturally heterogeneous samples can withstand without compromising one's results.

Second, for some questions and sample distributions, the effects of storage time on fecal steroid concentrations may also be controlled during data analysis. The small error bars at each time point in the laboratory study suggest that one strategy would be to analyze and compare samples that have been subjected to similar storage regimes. Similarly, one could analyze steroid concentrations relative to the average concentration for the month in which they were collected thereby generating residual values that can be compared. This approach needs to be taken with considerable attention to decide what values to average to generate meaningful residual data for comparisons, such as whether to pool data for males and females or across age classes in the average. The validity of particular analytic strategies will depend on the particular questions, reasonable assumptions, sample sizes, and sampling regimes in each instance.

Third, if long-term storage of fecal samples in ethanol is unavoidable, then researchers will need to validate their chosen storage method for each hormone of interest. Our findings underscore the importance of thorough validation of methods as a precursor to any work conducted with fecal steroids. Future work on field techniques might include long-term validation of other storage techniques, such as oven drying, which has been shown to be stable over three weeks for some hormones (Brockman and Whitten, 1996), field extraction into aqueous solutions (Lynch et al., 2002; Strier et al., 1999), or the addition of preservatives to the ethanol.

Fourth, the source of changes occurring during longterm storage may need to be identified to determine exactly what actions are most appropriate to ameliorate storage effects. Several possible explanations for the changes reported here illustrate the potential importance of identifying the source of changes. Stability studies of glucocorticoids conducted in feces (Wasser et al., 1988), urine (Brown et al., 1995), and pure preparations (Isaksson et al., 2000) report steroid deterioration under conditions of ambient temperature storage. The decline in fGC and fE concentrations after 120 or 90 days, respectively, may be caused by deterioration of the metabolites. Paradoxically, however, our results show increasing fecal hormone concentrations over a considerable time period.

The observed pattern of increasing concentrations may be an artifact of using a group-specific antibody as opposed to a highly specific cortisol or estradiol antibody. A group-specific antibody cross-reacts with a family of metabolites derived from the parent hormone (Palme and Moestl, 1997; Schwarzenberger et al., 1997; Wasser et al., 2000), while a highly specific antibody cross-reacts only with the parent hormone itself. Evidence that group-specific antibodies show different sensitivities to changing glucocorticoid or estrogen metabolites over time is provided by this study and three others. Studies using highly specific antibodies demonstrated deteriorating urinary cortisol metabolites (Brown et al., 1995) and fecal estrogen metabolites (Wasser et al., 1988) when samples were stored at ambient temperature. In contrast, studies using groupspecific antibodies (Palme and Moestl, 1997) showed increasing fecal cortisol (Moestl et al., 1999, this study)
296

297

298

299

300

301

302

303

304

305

306

307

308

309

310

311

312

313

314

315

316

317

318

319

320

321

322

323

324

325

326

327

328

329

330

331

332

333

334

335

336

337

338

339

340

341

342

343

344

345

346

347

348

349

350

351 
and estrogen (this study) metabolite concentrations in samples stored at ambient temperature.

While the use of a group-specific antibody may have made the observed changes greater, we do not suggest that exclusive use of highly specific antibodies is necessary for fecal steroid measurements. Rather, the decision to use a group-specific or highly specific antibody should be determined by the hormone of interest and the steroid metabolism pathways in the study species. Storage effects should be prevented through storage regimes that are determined in part by what is chemically occurring within the samples over time. Below, we discuss three chemical explanations for our results, noting that these explanations are not mutually exclusive. In Table 3, we present predictions for temporal and HPLC analyses of samples subjected to a storage study similar to this one. We also propose practical solutions for the laboratory or field to ameliorate storage effects given each scenario.

First, the observed pattern may be caused by the ethanol solution increasingly extracting metabolites from the feces at ambient temperatures. This hypothesis questions the assumption that spiking samples with pure corticosterone or estradiol preparations prior to extraction is an accurate measure of the extraction efficiency of all cortisol or estradiol metabolites. It is possible that some immunoreactive metabolites have lower extraction efficiencies than pure preparations. Immunoreactive metabolites with normally low extraction efficiencies might have a higher extraction efficiency when stored in ethanol for several months at ambient temperature. These metabolites would be deposited on the surface of the fecal material during ethanol evaporation step and freeze-drying process, and would go into solution more easily during the extraction step than if the sample had not undergone long-term storage in ethanol (see Section 2).

Second, immunoreactive metabolites could be derived from the breakdown or deconjugation of multiply conjugated steroid metabolites into mono-conjugated or unconjugated metabolites. In the baboon, $11 \%$ of fecal cortisol metabolites are conjugated (Wasser et al., 2000), while $20 \%$ of estradiol is excreted as estradiol sulfate in feces (Wasser et al., 1994), making this a likely explanation for our results. The rate of deconjugation may be increased by storage in highly ethanolic solutions because conjugates are more stable in aqueous solutions (Ziegler, personal communication). That ethanol may be contributing to the observed chemical changes is supported by the observation of increased fGC concentrations, even in samples stored in ethanol at sub-zero temperatures.

Third, fecal metabolites related to the parent hormone may be oxidized in the ethanol solution. The formation of hydroxyl groups on fecal metabolites may result in increased affinity of these molecules to the primary antibody used in our assays (Moestl, personal communication). A group-specific antibody may have a greater affinity for these oxidized metabolites than a highly specific antibody. High rates of both deconjugation and oxidation may contribute to the increase in measured metabolites at the beginning of the experiment.

Despite inherent complications, some which have been identified in this paper, fecal steroid techniques are capable of answering a variety of physiological questions that otherwise might remain intractable in free-

Table 3

Three hypotheses proposed to explain the chemical changes that may be occurring during long-term storage of fecal samples in ethanol and suggested practical solutions

\begin{tabular}{|c|c|c|c|c|c|}
\hline \multirow[t]{2}{*}{ Hypothesis } & & \multirow[t]{2}{*}{ Temporal pattern } & \multicolumn{2}{|l|}{ HPLC } & \multirow[t]{2}{*}{ Solution } \\
\hline & & & $\begin{array}{l}\text { Fraction } \\
\text { location }\end{array}$ & $\begin{array}{l}\text { Fraction } \\
\text { magnitude }\end{array}$ & \\
\hline $\begin{array}{l}\text { Extraction } \\
\text { efficiency }\end{array}$ & & $\begin{array}{l}\text { Increasing over time, } \\
\text { followed by a decline }\end{array}$ & Stable & Increasing & Extract samples ASAP after collection \\
\hline \multirow[t]{2}{*}{$\begin{array}{l}\text { Metabolite } \\
\text { deconjugation }\end{array}$} & $\begin{array}{l}\text { Before hydrolysis } \\
\text { and solvolysis }\end{array}$ & $\begin{array}{l}\text { Increasing over time, } \\
\text { followed by a decline }\end{array}$ & Stable & Changing & $\begin{array}{l}\text { Treat all samples with sequential hydrolysis } \\
\text { and solvolysis }\end{array}$ \\
\hline & $\begin{array}{l}\text { After hydrolysis } \\
\text { and solvolysis }\end{array}$ & $\begin{array}{l}\text { Constant, followed by a } \\
\text { decline }\end{array}$ & Stable & Constant & \\
\hline $\begin{array}{l}\text { Metabolite } \\
\text { oxidation }\end{array}$ & & $\begin{array}{l}\text { Increasing over time, } \\
\text { followed by a decline }\end{array}$ & Changing & Changing & $\begin{array}{l}\text { Limit the time samples that are stored in } \\
\text { ethanol at room temperature }{ }^{b}\end{array}$ \\
\hline
\end{tabular}

Temporal pattern refers to predicted pattern of concentrations measured in samples assayed at time intervals. HPLC refers to the predicted results for each type of chemical change when samples are analyzed by high performance liquid chromatography and the subsequent fractions analyzed with RIA. Depending on the exact method, HPLC can generate 40 fractions. RIA determines which of the 40 fractions are immunoreactive and the relative concentration of immunoreactive compounds in each fraction. The location (e.g., fractions 2 , 8 , and 20 are immunoreactive, while the remaining 37 are not) and the magnitude (i.e., concentration) of fractions changes according to the chemical changess occurring in the sample.

${ }^{a}$ Sequential hydrolysis and solvolysis liberate steroids from their conjugate enabling the measurement of total fecal steroid concentrations (Ziegler et al., 1996; Ziegler et al., 1997a,b). Alternatively, conjugates, may be stabilized in the field by extracting fecal steroids into an aqueous solution (distilled water:ethanol::50:50, Lynch et al., 2002; Strier and Ziegler, 1997; Strier et al., 1999). However, further validation is needed to determine if ambient temperature storage of these extracts is feasible.

${ }^{\mathrm{b}}$ A group-specific antibody may be more likely to detect this kind of chemical change than a highly specific antibody. Therefore, time limits on storage in ethanol may vary according to the type of antibody used in the RIA. 
416 living populations of large social animals. While storage 417 effects may confound the ability to detect subtle physi418 ological differences between individuals, fecal steroid 419 techniques are capable of identifying large differences 420 between study groups. For example, non-invasive fecal 421 steroid techniques have been used (1) to study popula422 tion dynamics (Berger et al., 1999), (2) to assess capture 423 techniques (Creel et al., 1997), and (3) to examine the 424 interface between hormones and behavior (Brockman 425 and Whitten, 1996; Brockman et al., 1998; Cavigelli, 426 1999; Cavigelli and Pereira, 2000; Lynch et al., 2002; 427 Scheibe et al., 1999; Strier and Ziegler, 1997, 2000; Strier 428 et al., 1999). The ability to answer more fine-grained 429 questions will be enhanced when field storage methods 430 are improved to reduce or eliminate the variability in431 troduced by various storage regimes.

432 While our results provide some guidance for field 433 workers, they generate a number of additional ques434 tions. Some questions that warrant future attention are: 435 (1) To what extent are the observed dynamics species436 specific? (2) How does the initial concentration of these 437 samples influence reaction dynamics? (3) Do tempera438 ture and initial concentrations interact at ambient tem439 peratures and at temperatures below $-20^{\circ} \mathrm{C}$ ? (4) Can 440 this problem be ameliorated by using more specific an441 tibodies, different preservatives, or extracting samples 442 into aqueous ethanol? Field experiments will comple443 ment laboratory ones in answering these questions and 444 enhancing the potential of non-interventive field sam445 pling for physiological investigations.

\section{Acknowledgments}

447 Support was provided by the US National Science 448 Foundation (IBN 9985910) and the Chicago Zoological 449 Society. We thank M. Pruett-Jones, C. Demitros, and J. 450 Petersen and veterinary services at the Brookfield Zoo 451 for collecting and shipping the baboon samples from 452 Chicago to Princeton. Discussions with S. Wasser and 453 T.E. Ziegler stimulated us to conduct this project. M. 454 Hau, M.S. Khan, M. Wikelski, and T.E. Ziegler con455 tributed ideas during its development. S. Alberts, S. 456 Altmann, T. Good, J.W. Lynch, E. Moestl, and E. Pride 457 commented on previous drafts of the manuscript.

\section{References}

463 Brockman, D.K., Whitten, P.L., 1996. Reproduction in free-ranging 464
Brockman, D.K., Whitten, P.L., Richard, A.F., Schneider, A., 1998. Reproduction in free-ranging male Propithecus verreauxi: The hormonal correlates of mating and aggression. American Journal of Physical Anthropology 105, 137-151.

Brown, J., Wemmer, C., Lehnhardt, J., 1995. Urinary cortisol analysis for monitoring adrenal activity in elephants. Zoo Biology 14, 533542.

Cavigelli, S., 1999. Behavioural patterns associated with faecal cortisol levels in free-ranging female ring-tailed lemurs, Lemur catta. Animal Behaviour 57, 935-944.

Cavigelli, S., Pereira, M., 2000. Mating season aggression and fecal testosterone levels in male ring-tailed lemurs. Hormones and Behavior 37, 246-255.

Creel, S., Creel, N., Monfort, S., 1997. Radiocollaring and stress hormones in African wild dogs. Conservation Biology 11, 544-548.

Curtis, D., Zaramody, A., DI, G., Pickard, A., 2000. Non-invasive monitoring of reproductive status in wild mongoose lemurs (Eulemur mongoz). Reproduction, Fertility and Development 12, 21-29.

Goymann, W., Moestl, E., Van't Hof, T., East, M.L., Hofer, H., 1999. Non-invasive fecal monitoring of glucocorticoids in spotted hyenas, Crocuta crocuta. General and Comparative Endocrinology $114,340-348$.

Graham, L., Brown, J., 1996. Cortisol metabolism in the domestic cat and implications for non-invasive monitoring of adrenocortical function in endangered felids. Zoo Biology 15, 71-82.

Hamilton, R.A., Stanton, P.G., O’Donnell, L., Steele, V.R., Taggart, D.A., Temple-Smith, P.D., 2000. Determination of seasonality in southern hairy-nosed wombats (Lasiorhinus latifrons) by analysis of fecal androgens. Biology of Reproduction 63, 526-531.

Isaksson, M., Gruvberger, B., Persson, L., Bruze, M., 2000. Stability of corticosteroid patch test preparations. Contact Dermatitis 42,144 148.

Lynch, J.W., Ziegler, T.E., Strier, K.B., 2002. Individual and seasonal variation in fecal testosterone and cortisol levels of wild male tufted capuchin monkeys (Cebus apella nigritus). Hormones and Behavior 41, 275-287.

Moestl, E., Messmann, S., Bagu, E., Robia, C., Palme, R., 1999 Measurement of glucocorticoid metabolite concentrations in faeces of domestic livestock. Journal of Veterinary Medicine Series A 46, 621-631.

Neter, J., Wasserman, W., Kutner, M., 1990. Applied linear statistical models: regression, analysis of variance and experimental designs. Irwin, Homewood, Illinois.

Palme, R., Moestl, E., 1997. Measurement of cortisol metabolites in faeces of sheep as a parameter of cortisol concentration in the blood. International Journal of Mammalian Biology 62 (Suppl. 2), 192-197.

Sapolsky, R.M., Altmann, J., 1991. Incidence of hypercortisolism and dexamethasone resistance increases with age among wild baboons. Biological Psychiatry 30, 1008-1016.

Scheibe, K.M., Dehnhard, M., Meyer, H.H.D., Scheibe, A., 1999. Non-invasive monitoring of reproductive function by determination of faecal progestagens and sexual behaviour in a herd of Przewalski mares in a semireserve. Acta Theriologica 44, 451-463.

Schwarzenberger, F., Palme, R., Bamberg, E., Mostl, E., 1997. A review of faecal progesterone metabolite analysis for non-invasive monitoring of reproductive function in mammals. Journal of Mammalian Biology 62, 214-221.

Sousa, M.B.C., Ziegler, T.E., 1998. Diurnal variation on the excretion patterns of fecal steroids in common marmoset (Callithrix jacchus) females. American Journal of Primatology 46, 105-117.

Stavisky, R., Russell, E., Stallings, J., Smith, E.O., Worthman, C., Whitten, P.L., 1995. Fecal steroid analysis of ovarian cycles in freeranging baboons. American Journal of Primatology 36, 285-297.

Stoops, M.A., Anderson, G.B., Lasley, B.L., Shideler, S.E., 1999. Use of fecal steroid metabolites to estimate the pregnancy rate of a free-
467 


\section{4}

535

536

537

538

539

540

541

542

543 Strier, K., Ziegler, T., 2000. Lack of pubertal influences on female 544

ranging herd of tule elk. Journal of Wildlife Management 63, 561569.

Strier, K., Ziegler, T., 1997. Behavioral and endocrine characteristics of the reproductive cycle in wild muriqui monkeys, Brachyteles arachnoides. American Journal of Primatology 42, 299-310.

Strier, K.B., Ziegler, T.E., Wittwer, D.J., 1999. Seasonal and social correlates of fecal testosterone and cortisol levels in wild male muriquis (Brachyteles arachnoides). Hormones and Behavior 35, 125-134.

Strier, K., Ziegler, T., 2000. Lack of pubertal influences on female
dispersal in muriqui monkeys. Animal Behaviour 59, 849-860.

Wallner, B., Moestl, E., Dittami, J., Prossinger, H., 1999. Fecal glucocorticoids document stress in female Barbary macaques ( $\mathrm{Mac}$ aca sylvanus). General and Comparative Endocrinology 113, 80-86.

Wasser, S., 1996. Reproductive control in wild baboons measured by fecal steroids. Biology of Reproduction 55, 393-399.

Wasser, S., Risler, L., Steiner, R., 1988. Excreted steroids in primate feces over the menstrual cycle and pregnancy. Biology of Reproduction 39, 862-872.

Wasser, S.K., Monfort, S.L., Southers, J., Wildt, D.E., 1994. Excretion rates and metabolites of estradiol and progesterone in baboon (Papio cynocephalus cynocephalus) feces. Journal of Reproduction and Fertility 101, 213-220.

Wasser, S., Bevis, K., King, G., Hanson, E., 1997. Non-invasive physiological measures of disturbance in the northern spotted owl. Conservation Biology 11, 1019-1022.
Wasser, S., Hunt, K., Brown, J., Cooper, K., Crockett, C., Bechert, U., 560 Millspaugh, J., Larson, S., Monfort, S., 2000. A generalized fecal 561 glucocorticoid assay for use in a diverse array of non-domestic 562 mammalian and avian species. General and Comparative Endo- 563 $\begin{array}{ll}\text { crinology 120, 260-275. } & 564\end{array}$

Whitten, P.L., Brockman, D.K., Stavisky, R.C., 1998. Recent 565 advances in non-invasive techniques to monitor hormone-behavior 566 interactions. Yearbook of Physical Anthropology 41, 1-23. 567

Ziegler, T.E., Scheffler, G., Wittwer, D.J., Schultz-Darken, N., 568 Snowdon, C.T., Abbott, D.H., 1996. Metabolism of reproductive 569 steroids during the ovarian cycle in two species of callitrichids, 570 Saguinus oedipus and Callithrix jacchus, and estimation of the 571 ovulatory period from fecal steroids. Biology of Reproduction 54, 572 91-99.

Ziegler, T.E., Santos, C.V., Pissinatti, A., Strier, K.B., 1997a. Steroid 574 excretion during the ovarian cycle in captive and wild muriquis, 575 Brachyteles arachnoides. American Journal of Primatology 42, 311- 576 $\begin{array}{ll}321 . & 577\end{array}$

Ziegler, T.E., Scheffler, G., Carlson, A., 1997b. Methods and use of 578 fecal steroid analyses for monitoring reproductive functioning 579 in marmosets and tamarins. A Primatologia no Brasil 6, 269- 580 $280 . \quad 581$

Ziegler, T., Hodges, K., Winkler, P., Heistermann, M., 2000. 582 Hormonal correlates of reproductive seasonality in wild female 583 Hanuman langurs (Presbytis entellus). American Journal of 584 Primatology 51, 119-134. 